\title{
Apoplexy in sporadic pituitary adenomas: a single referral center experience and AIP mutation analysis
}

\author{
Christhiane Fialho' \\ https://orcid.org/0000-0003-3178-957X \\ Monique Álvares Barbosa ${ }^{2}$ \\ https://orcid.org/0000-0002-2379-6596 \\ Carlos Henrique Azeredo Lima $^{3}$ \\ https://orcid. org/0000-0002-2299-4814 \\ Luiz Eduardo Armondi Wildemberg ${ }^{1,4}$ \\ https://orcid.org/0000-0002-2692-4960 \\ Mônica R. Gadelha' 1,3 \\ https://orcid. org/0000-0002-9250-3558 \\ Leandro Kasuki 1,4,5 \\ https://orcid.org/0000-0003-1339-3192
}

\begin{abstract}
Objective: To analyze the clinical, laboratory, and radiological findings and management of patients with clinical pituitary apoplexy and to screen for aryl hydrocarbon receptor-interacting protein (AIP) mutations. Subjects and methods: The clinical findings were collected from the medical records of consecutive sporadic pituitary adenoma patients with clinical apoplexy. Possible precipitating factors, laboratory data, magnetic resonance imaging (MRI) findings and treatment were also analyzed. Peripheral blood samples were obtained for DNA extraction from leukocytes, and the entire AIP coding region was sequenced. Results: Thirty-five patients with pituitary adenoma were included, and $23(67 \%)$ had non-functioning pituitary adenomas. Headache was observed in $31(89 \%)$ patients. No clear precipitating factor was identified. Hypopituitarism was observed in $14(40 \%)$ patients. MRI from 20 patients was analyzed, and $10(50 \%)$ maintained a hyperintense signal in MRI performed more than three weeks after pituitary apoplexy (PA). Surgery was performed in ten (28\%) patients, and 25 $(72 \%)$ were treated conservatively with good outcomes. No AIP mutation was found in this cohort. Conclusion: Patients with stable neuroophthalmological impairments can be treated conservatively if no significant visual loss is present. Our radiological findings suggest that hematoma absorption lasts more than that observed in other parts of the brain. Additionally, our study suggests no benefits of AIP mutation screening in sporadic patients with apoplexy. Arch Endocrinol Metab. 2021;65(3):295-304
\end{abstract}

Keywords

Apoplexy; pituitary adenomas; AIP; familial isolated pituitary adenomas
${ }^{1}$ Centro de Pesquisas em Neuroendocrinologia/Seção de Endocrinologia, Faculdade de Medicina e Hospital Universitário Clementino Fraga Filho, Universidade Federal do Rio de Janeiro, Rio de Janeiro, RJ, Brasil ${ }^{2}$ Unidade de Radiologia, Instituto Estadual do Cérebro Paulo Niemeyer, Secretaria Estadual de Saúde, Rio de Janeiro, RJ, Brasil

${ }^{3}$ Laboratório de Neuropatologia e Genética Molecular, Instituto Estadual do Cérebro Paulo Niemeyer, Secretaria Estadual de Saúde, Rio de Janeiro, RJ, Brasil ${ }^{4}$ Unidade de Neuroendocrinologia, Instituto Estadual do Cérebro Paulo Niemeyer, Secretaria Estadual de Saúde, Rio de Janeiro, RJ, Brasil ${ }^{5}$ Seção de Endocrinologia, Hospital Federal de Bonsucesso, Rio de Janeiro, RJ, Brasil

Correspondence to

Leandro Kasuki

Centro de Pesquisas em

Neuroendocrinologia, Hospita

Universitário Clementino Fraga Filho, Universidade Federal do Rio de

Janeiro

Rua Professor Rodolpho Paulo Rocco, 255, sala 9F, Ilha do Fundão - 21941913 - Rio de Janeiro, RJ, Brasil

Ikasuki@yahoo.com

Received on Aug/30/2020 Accepted on Nov/24/2020

DOI: 10.20945/2359-3997000000358

\section{INTRODUCTION}

$\mathrm{P}$ ituitary apoplexy (PA) is an acute event associated with hemorrhage or infarction and occurs in approximately $2 \%$ to $12 \%$ of those with a preexisting pituitary adenoma (1-4). Sudden, abrupt and intense headache, visual impairment, an altered level of consciousness and clinical manifestations of hypopituitarism are described in the acute onset of PA (2-6).

The pathophysiology of apoplexy involves changes in the pituitary blood supply and can be related to rapid tumor enlargement that increases metabolic demand and intrasellar pressure, leading to the compression of adjacent structures (7). Therefore, PA occurs mostly in macroadenomas (8-10). Similarly, nonfunctioning pituitary adenomas (NFPAs) are the most prevalent in a series of apoplexy, likely related to silent growth, identified only after the development of a mass effect $(3,9,11)$.

Risk factors for PA have not been completely elucidated, and potential precipitating factors were identified in $10 \%$ to $40 \%$ of cases, including angiography 
procedures, cardiac and other major surgeries, dynamic pituitary function tests, arterial hypertension, radiation therapy, head trauma, anticoagulation and antiplatelet therapy $(2,9,12-14)$. Estrogen therapy, coagulopathies and intense exercise were also reported. Some case reports described PA during the treatment of acromegaly with octreotide (15).

Computed tomography (CT) is generally the first imaging tool available in the emergency room and can detect pituitary expansive masses in up to $80 \%-94 \%$ of cases, but a PA diagnosis is made in only $21 \%$ to $28 \%$ of cases $(6,15,16)$. Magnetic resonance imaging (MRI) is the better choice for image analysis, confirming the diagnosis of PA in approximately $90 \%$ of patients $(3,6,8,16)$.

No consensus exists concerning the best PA approach, and treatment can be conservative or surgical according to each case and condition $(16,17)$. Some studies have demonstrated a good response in visual recovery with conservative management, considering selected patients with non-progressive neuroophthalmological deficits $(6,18,19)$. During the acute phase, all the patients with clinical findings of suspected apoplexy must be tested for hypopituitarism, mainly because of the risk of severe hypocortisolism (2).

Interestingly, some series described $\mathrm{PA}$ as a feature of patients harboring germline mutations in the aryl bydrocarbon receptor-interacting protein $(A I P)$ gene (20-22). Typically, patients with AIP mutations (AIPmuts) have macroadenomas of young onset and aggressive behavior $(20,21,23-25)$. AIPmuts are present in approximately $20 \%$ of familial isolated pituitary adenoma (FIPA) kindreds and in 3.6\% to $20 \%$ of apparently sporadic adenomas varying according to the age of the group analyzed, but mutations have low penetrance in both groups $(21,22,26-28)$. To date, the frequency of $A I P$ muts in patients with apparently sporadic pituitary adenomas presenting with $\mathrm{PA}$ is unknown.

Our study analyzed the clinical, radiological and therapeutic characteristics of patients who presented with clinical PA and were referred to a specialized neurosurgery center. We also evaluated the frequency of AIPmuts in these apparently sporadic pituitary adenoma patients.

\section{SUBJECTS AND METHODS}

\section{Patients}

We retrospectively analyzed the files in our database from consecutive patients referred to a neurosurgery center
[Instituto Estadual do Cérebro Paulo Niemeyer(IECPN)] with a clinical history and MRI report of PA from August 2013 to September 2017. We included patients who presented with sudden onset of severe headache and/or other neuroophthalmological symptoms (visual disturbance and/or ophthalmoplegia and/or altered consciousness) diagnosed with PA according to the UK Guidelines for the Management of Pituitary Apoplexy and who had undergone MRI to confirm PA (2). Headache was classified as thunderclap headache when it was described as bilateral and retroocular, with abrupt onset associated with progression to maximum intensity within a few minutes (29).

Blood samples were collected from the patients for genetic analysis (performed in our laboratory). At that time, they were interviewed to clarify all the symptoms presented at the acute phase. On admission, visual fields were assessed by confrontation tests and Goldmann manual campimetry.

Patients with clinical features and/or a history of $\mathrm{X}$-linked acrogigantism (XLAG), multiple endocrine neoplasia type 1 (MEN-1) and 4 (MEN-4), Carney complex (CNC), association of pheochromocytoma/ paraganglioma and pituitary adenoma syndrome (3PAs) and FIPA were excluded. All the subjects signed written informed consent, and the Ethics Committee of Medical School and Hospital Universitário Clementino Fraga Filho (HUCFF) of Universidade Federal do Rio de Janeiro (UFRJ) approved the study.

\section{METHODS}

\section{Laboratory analyses}

We collected the serum basal levels of growth hormone (GH), insulin-like growth factor type I (IGF-I), prolactin (PRL), thyroid-stimulating hormone (TSH), free thyroxine (FT4) and total testosterone (in males) from patient files. Women with regular menstrual cycles who did not use oral contraceptives were considered to have no gonadotropic axis deficiency. In postmenopausal women, the FSH levels were analyzed. We could not evaluate the presence of hypocortisolism in all the patients because some patients were transferred from other centers and were being treated with high doses of dexamethasone or hydrocortisone before admission to our center or were using oral corticosteroids. Hypopituitarism was defined as the presence of at least one endocrine axis. 
We collected laboratory results reported at admission and at the last evaluation at IECPN until September 2017. The laboratory tests recorded at admission were performed, in cases, outside IECPN, at different laboratories.

\section{Radiological evaluation}

All the patients had at least one MRI described in the medical records confirming PA. Twenty of the 35 patients had undergone MRI at our center, and these MRI images were available in our database system. The MRIs of these 20 patients were reviewed by the same experienced neuroradiologist that analyzed the sagittal and coronal Tl-weighted images (TlWI), with and without gadolinium contrast, and coronal T2-weighted images (T2WI).

Microadenomas were defined as those with a maximum diameter $<10 \mathrm{~mm}$, and macroadenomas were defined as those with a maximum diameter $\geq 10$ $\mathrm{mm}$ (30). The tumor volume was estimated using the DiChiro and Nelson formula (width $\times$ height $\times$ length $\times 0.5233)(31)$. Patients were grouped according to the MRI findings using the classification of typical stages of hematoma evolution in the brain, as shown in Table l (32).

\section{Screening for AIP mutations}

We used the PureGene Blood Kit (Gentra, Minneapolis, $\mathrm{MN}, \mathrm{USA}$ ) to obtain genomic DNA from $300 \mu \mathrm{L}$ of whole blood following the manufacturer's instructions. DNA was resuspended in $100 \mu \mathrm{L}$ of DNA Hydration Solution (Gentra). After extraction, PCR was performed using an Applied Biosystem ProFlex ${ }^{\mathrm{TM}}$ PCR System (Thermo Fisher Scientific, Foster City, CA, USA).

Genomic analyses included exons 1 to 6 from the AIP gene and flanking intronic sequences. Amplification and sequencing were performed using AIP PCR/Sanger Sequencing Primer pairs (Thermo Fisher Scientific ${ }^{\mathrm{TM}}$, Boston, MA). The reaction contained a mixture of 30 ng of genomic DNA, 2 U of Platinum ${ }^{\circledR}$ Taq DNA Polymerase (Invitrogen, Foster City, CA, USA), 1.5 $\mathrm{mM} \mathrm{MgCl}$ and $0.2 \mu \mathrm{M}$ of each primer, with a total volume of $25 \mu \mathrm{L}$ (Table 2 ).

PCRs followed an initial denaturation and enzyme activation at $94{ }^{\circ} \mathrm{C} / 5 \mathrm{~min}$ and then 40 cycles of denaturation at $94{ }^{\circ} \mathrm{C} / 45 \mathrm{sec}$, annealing at $94^{\circ} \mathrm{C} / 45$

Table 1. Stages of hematoma as observed on MRI

\begin{tabular}{lccc}
\hline Stage & Time since apoplexy & Hemoglobin & T1WI \\
\hline Acute & $\leq 7$ days & Deoxyhemoglobin & T2WI \\
& $>7$ days to $\leq 21$ days & Methemoghtly Hyperintense & Very Hypointense \\
Subacute & $>21$ days & Hemosiderin & Hyperintense \\
Chronic & Hyperintense & Hypointense \\
\hline
\end{tabular}

MRI: magnetic resonance imaging; T1Wl: T1-weighted imaging; T2Wl: T2-weighted imaging. Radiological classification of hematoma evolution on MRI (32).

Table 2. Primers used for AIP gene sequencing

\begin{tabular}{|c|c|c|c|c|}
\hline \multicolumn{5}{|c|}{ PRIMERS } \\
\hline Cat $N^{\circ}$ & Lot $n^{\circ}$ & Description/Sequence & Exon & Product size \\
\hline A15633 - Hs00394559 & 292760 G02 & TGTAAAACGACGGCCAGTCCGAGACATTCCTAGGCTCCG & \multirow[t]{2}{*}{1} & \multirow[t]{2}{*}{495} \\
\hline A15634 - Hs00394559 & 292788 B02 & CAGGAAACAGCTATGACCGCCCGAATTCACCCCCTACTTAAA & & \\
\hline A15633 - Hs00394560 & 292760 G03 & TGTAAAACGACGGCCAGTGGAAGCCCCGTCCCTTATGC & \multirow[t]{2}{*}{2} & \multirow[t]{2}{*}{381} \\
\hline A15634 - Hs00394560 & 292788 B03 & CAGGAAACAGCTATGACCAGTCTAGCAGAGGGTGGAGGGAG & & \\
\hline A15633 - Hs00394561 & 292760 G04 & TGTAAAACGACGGCCAGTCGGAGTAGGGTCCCAGTTGTC & \multirow[t]{2}{*}{3} & \multirow[t]{2}{*}{492} \\
\hline A15634 - Hs00394561 & 292760 G07 & CAGGAAACAGCTATGACCGGAGACCCAGGGTACTGCCAA & & \\
\hline A15633 - Hs00394562 & 292760 G05 & TGTAAAACGACGGCCAGTCCAGATGTGGGTCAGGTCTGC & \multirow[t]{2}{*}{4} & \multirow[t]{2}{*}{501} \\
\hline A15634 - Hs00394562 & 292788 B04 & CAGGAAACAGCTATGACCGTCGTACTTGTTGAGGATGGAAGA & & \\
\hline A15633 - Hs00394563 & 292788 B01 & TGTAAAACGACGGCCAGTAAGGTACTGCCTGGAGGCTGAG & \multirow[t]{2}{*}{5} & \multirow[t]{2}{*}{507} \\
\hline A15634 - Hs00394563 & 292788 B05 & CAGGAAACAGCTATGACCTCATGTCTCCTGGCACCATGGG & & \\
\hline A15633 - Hs00394564 & 292760 G06 & TGTAAAACGACGGCCAGTGTGGCATCCTCAGGTCAGGGA & \multirow[t]{2}{*}{6} & \multirow[t]{2}{*}{509} \\
\hline A15634 - Hs00394564 & 292788 B06 & CAGGAAACAGCTATGACCGTACCAGGAATGCCAGGTGATGAC & & \\
\hline
\end{tabular}

AIP: aryl hydrocarbon receptor-interacting protein. 
sec and extension at $72{ }^{\circ} \mathrm{C} / 1 \mathrm{~min}$. A final extension was performed at $72{ }^{\circ} \mathrm{C}$ for $7 \mathrm{~min}$. PCR product clean-up was performed using the ExoSAP-IT ${ }^{\circledR}$ system (USB Corporation, Cleveland, OH, USA), and DNA sequencing using the Big Dye Terminator v3.1 Cycle Sequencing kit (Thermo Fisher Scientific).

The products were sequenced in both directions on an ABI 3130xl Genetic Analyzer (Applied Biosystems), and electropherogram-derived sequences were aligned using Benchiling (https://benchiling. $\mathrm{com} /$ ) and BioEditsoftware (http://www.mbio. ncsu.edu/BioEdit/bioedit.html). The reference sequences for the AIP gene used were as follows: ENSG00000110711 (https://www.ensembl.org/ Homo_sapiens/Gene/Summary?g=ENSG000001 10711;r=11:67483041-67491103), NG_008969.3 (https://www.ncbi.nlm.nih.gov/protein / NP_003968) and NM_003977.3 (https://www.ncbi. nlm.nih.gov/nuccore/NM_003977).

\section{Statistical analysis}

SPSS version 23.0 for Windows was used for statistical analysis, and the data were presented as percentages, means \pm standard deviation (SD) or medians (min-max). Normal distribution was tested, and the Mann-Whitney test was used to compare numerical variables between groups. A p-value $<0.05$ was considered significant.

\section{RESULTS}

\section{Demographical and tumor characteristics}

Thirty-five patients were included (20 males), with a mean age of $40.5 \pm 17.1$ years. Non-functioning pituitary adenomas were present in 23 patients $(66 \%)$, seven $(20 \%)$ harbored somatotropinomas, and five (14\%) harbored prolactinomas. Only three patients $(9 \%)$ had a previous diagnosis of pituitary adenoma before apoplexy: two patients harboring NFPA and one acromegaly patient. Only the acromegaly patient had started treatment before the PA episode (octreotide LAR four months before). The others were treatment naïve.

\section{Clinical characteristics}

Headache was the most common symptom, present in 31 patients $(89 \%)$. Among these, 16 patients $(52 \%)$ presented with a thunderclap headache, ophthalmoplegia was observed in 13 patients (37\%), and six patients (17\%) presented with ptosis. Ten $(28 \%)$ patients presented with visual field defects, and changes in the level of consciousness were present in five (14\%) patients. Five (14\%) patients presented with ophthalmoplegia and visual loss concomitantly. At the last assessment, 9 (25\%) patients persisted with some degree of visual field defects. No patient presented headache or a reduced level of consciousness at the last evaluation. The median period between admission and last evaluation was six months (ranging from 3 to 48 months). The clinical presentation data are summarized in Table 3.

Table 3. Clinical findings

\begin{tabular}{lcc}
\hline Symptoms & $\begin{array}{c}\text { At acute } \\
\text { event } \\
\text { N (\%) }\end{array}$ & $\begin{array}{c}\text { At last } \\
\text { evaluation* } \\
\text { N (\%) }\end{array}$ \\
\hline Headache & $31(89 \%)$ & 0 \\
Thunderclap headache & $16(46 \%)$ & 0 \\
Ophthalmological signs and symptoms ${ }^{\AA}$ & $18(51 \%)$ & $11(31 \%)$ \\
Ophthalmoplegia & $13(37 \%)$ & $03(8 \%)$ \\
Ptosis & $06(17 \%)$ & $02(6 \%)$ \\
Visual field defect & $10(28 \%)$ & $09(25 \%)$ \\
Altered consciousness & $05(14 \%)$ & 0 \\
\hline
\end{tabular}

*Median follow-up: 6 months after the event (range: 3 to 48 months).

\&Some patients presented more than one ophthalmological symptom.

\section{Laboratory characteristics}

At admission, 19 patients (54\%) had deficiency of at least one pituitary axis. Hypothyroidism was present in nine patients $(26 \%)$, and hypogonadism was also present in nine patients. None of them were using hormonal replacement before the acute event. We identified GH deficiency in six of 21 patients with IGF-I available at the first evaluation. Prolactin levels were available from 20 patients, and eight (20\%) patients had hyperprolactinemia. We observed worsening of hypothyroidism and hypogonadism at the last evaluation, with $17(48 \%)$ and $16(45 \%)$ patients presenting these deficiencies, respectively. The time elapsed from the acute PA event to the first laboratory evaluation varied from 3 days to 5 months. Considering the group of 10 patients treated surgically, three $(30 \%)$ improved pituitary function completely, two $(20 \%)$ presented worsening of the pituitary axis, and five (50\%) persisted with the same pre-operative hormonal deficits.

\section{Predisposing factors}

Potential predisposing factors were investigated, and no PA was found after cardiac surgery, radiotherapy, 
endocrinological function testing, and the use of anticoagulant medication or antiplatelet agents. Nine patients had arterial hypertension, and eight patients were using oral contraceptives; in one patient, the onset of PA occurred during intense exercise (running); in another patient, PA occurred four months after starting octreotide LAR treatment.

\section{Radiological characteristics}

In our cohort, one microadenoma $(9 \times 8 \times 7 \mathrm{~mm})$ was found. The median tumor volume in the whole group was $5.4 \mathrm{~cm}^{3}\left(0.26-48.67 \mathrm{~cm}^{3}\right)$, and the median larger tumor diameter was $2.9 \mathrm{~cm}(0.9-6.2 \mathrm{~cm})$. Somatotropinomas exhibited larger tumor diameters and volumes than other tumor types. The median tumor volumes were $26.9 \mathrm{~cm}^{3}\left(5.64-48.67 \mathrm{~cm}^{3}\right)$ and $4.5 \mathrm{~cm}^{3}(0.26-16.32)$ in acromegaly patients and other tumor types, respectively $(\mathrm{p}=0.021)$. The median larger tumor diameters were $4.2 \mathrm{~cm}(1.0$ to $6.2 \mathrm{~cm})$ and $2.5 \mathrm{~cm}(0.9$ to $4.5 \mathrm{~cm})$ in somatotropinomas and other tumor types, respectively $(\mathrm{p}=0.013)$. No significant difference was observed in the larger tumor diameter between groups with or without neuroophthalmological symptoms $(\mathrm{p}=0.18)$.

Considering the 20 MRIs available in our database that were reviewed by our neuroradiologist, various signal intensities of the pituitary adenomas in both TIWI and T2WI were observed, regardless of the elapsed time since apoplexy (Table 4 ). The time elapsed from acute PA to MRI varied from 3 days to 5 months; most of the patients ( 17 patients) were in the chronic phase. No clear pattern of evolution of the hemorrhagic image was observed after the episode of PA. Seventeen patients in this group presented with acute PA events more than three weeks before the MRI scan had been performed; in two of them, PA occurred five months before. However, in eight patients, a hyperintense signal in TlWI was still present; in six patients, a heterogeneous pattern (some areas of hyperintense

Table 4. Radiological findings

\begin{tabular}{|c|c|c|c|c|c|c|c|c|c|}
\hline Stages of Hematoma* & $\begin{array}{c}\Delta \mathrm{T} \\
\text { symptoms } \\
\text { and first } \\
\text { MRI at } \\
\text { IECPN }\end{array}$ & $\begin{array}{l}\text { Tumor } \\
\text { Type }\end{array}$ & T1 & T2 & $\begin{array}{c}\text { Optic } \\
\text { chiasma } \\
\text { compression }\end{array}$ & $\begin{array}{l}\text { High SI } \\
\text { in T1 }\end{array}$ & $\begin{array}{l}\text { Surgery } \\
\text { during the } \\
\text { follow-up }\end{array}$ & $\begin{array}{c}\Delta T \text { from } \\
\text { first to } \\
\text { last } \\
\text { MRI at } \\
\text { IECPN }\end{array}$ & $\begin{array}{l}\text { MRI findings } \\
\text { at last MRI }\end{array}$ \\
\hline \multicolumn{10}{|l|}{$\leq 7$ days } \\
\hline Acute & $3 d$ & ACRO & Hyperintense & Hyperintense & Yes & Yes & Yes & & \\
\hline Acute phase & $7 d$ & NFPA & Heterogenous & Heterogenous & Yes & Yes & No & & \\
\hline \multicolumn{10}{|l|}{$>7$ days and $\leq 21$ days } \\
\hline Subacute phase & $20 d$ & NFPA & Hyperintense & Hyperintense & Yes & Yes & Yes & & \\
\hline \multirow{17}{*}{$\begin{array}{l}>21 \text { days } \\
\text { Chronic }\end{array}$} & $28 d$ & NFPA & Hyperintense & Hyperintense & No & Yes & No & & \\
\hline & $28 d$ & NFPA & Hyperintense & Isointense & Yes & Yes & Yes & & \\
\hline & $28 d$ & NFPA & Heterogeneous & Heterogeneous & Yes & Yes & No & $3 \mathrm{~m}$ & Empty sella \\
\hline & $28 d$ & NFPA & Heterogeneous & Heterogeneous & Yes & Yes & Yes & & \\
\hline & $30 \mathrm{~d}$ & NFPA & Isointense & Isointense & No & No & No & $2 m$ & Heterogeneous \\
\hline & $30 d$ & NFPA & Hyperintense & Isointense & Yes & Yes & Yes & & \\
\hline & $2 m$ & PRL & Hyperintense & Heterogenous & No & Yes & No & & \\
\hline & $2 m$ & NFPA & Isointense & Hypointense & No & No & Yes & & \\
\hline & $2 m$ & NFPA & Heterogeneous & Hyperintense & Yes & Yes & Yes & & \\
\hline & $2 m$ & NFPA & Isointense & Heterogeneous & No & No & No & $5 \mathrm{~m}$ & Heterogenous \\
\hline & $2 m$ & NFPA & Heterogeneous & Heterogeneous & Yes & No & No & & \\
\hline & $3 m$ & ACRO & Isointense & Heterogeneous & No & No & Yes & & \\
\hline & $3 m$ & PRL & Isointense & Isointense & No & No & No & $7 \mathrm{~m}$ & Empty sella \\
\hline & $3 \mathrm{~m}$ & PRL & Hyperintense & Heterogeneous & No & Yes & Yes & & \\
\hline & $3 m$ & PRL & heterogeneous & Heterogeneous & Yes & Yes & Yes & & \\
\hline & $5 \mathrm{~m}$ & NFPA & Isointense & Heterogeneous & No & No & No & $8 \mathrm{~m}$ & Empty sella \\
\hline & $5 \mathrm{~m}$ & NFPA & Hyperintense & Hypointense & No & Yes & No & $8 \mathrm{~m}$ & Empty sella \\
\hline
\end{tabular}

MRI: magnetic resonance imaging; Sl: signal intensity; ACRO: somatotropinoma; NFPA: non-functioning pituitary adenoma; PRL: prolactinoma; d: days; m: months; T1 and T2 classification $\triangle$ T: time elapsed from PA to examination. 
signals and other areas of hypointense signals in TIWI at the same time) was observed.

We compared the first and last MRI scans of six patients who were treated conservatively. Progression to an empty sella was verified in four patients, and two patients maintained the heterogeneous pattern in the TIWI described above. The interval from the first to last MRI of these six patients was 5 months on average, ranging from three to eight months. No re-bleeding was observed. These radiological findings are summarized in Table 4. Figure 1 illustrates the MRI of a patient in the acute phase of PA.

\section{Treatment characteristics}

Seventeen (48\%) patients did not present any visual field impairment, ophthalmoplegia or ptosis and were treated conservatively. Eight (23\%) patients presented with only ophthalmoplegia and/or ptosis with no visual loss and received conservative treatment. All 10 (28\%) patients who presented visual loss had undergone surgery. In this group visual recovery was complete in one patient $(10 \%)$ and partial in three patients $(30 \%)$, and no improvement was observed in the remaining six $(60 \%)$ patients.

\section{AIP mutation screening}

No AIP mutation was identified. We found four different single-nucleotide polymorphism (SNP) variants: two intronic variants [c.132C $>\mathrm{T}$ p.Asp $44=$ in exon 2, c.516C $>\mathrm{T}$ p.Asp172 $=$ in exon 4] and two nonsynonymous variants [c.682 C>A and c.920 A>G] in exons 5 and exon 6 in 31 and 9 patients, respectively.

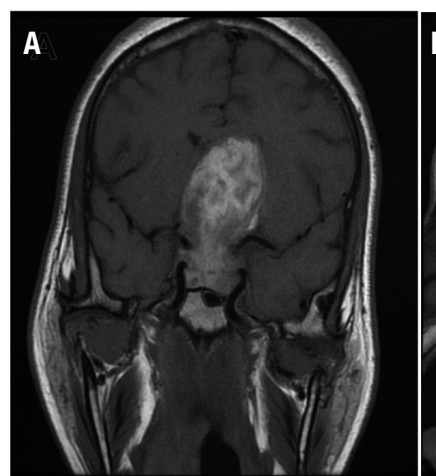

Cor T1WI

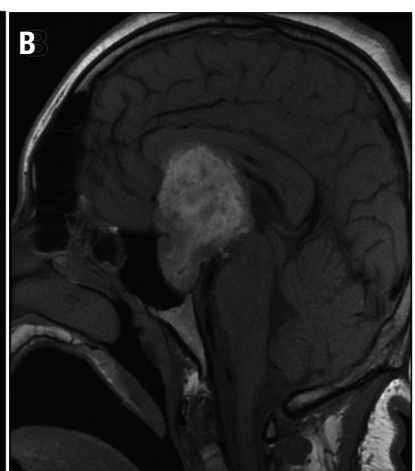

SagT1WI
Figure 1. Coronal $T 1$ (A) and sagittal $T 1$-weighted imaging (B) sequences of the magnetic resonance imaging of a 16-year-old patient performed three days after the pituitary apoplexy event and showing a mass in the sellar region with important suprasellar and infrasellar extension, presenting hyperintense areas.
The most frequent allelic variant (31 patients) was present in exon 5, c.682C >A, encoding Q228K. In exon 6, we found other nonsynonymous SNP variants, c.920A $>\mathrm{G}$, encoding Q370R (nine patients) and one intron variant insertion (c.788-30_788-29ins-/ TGCCCAC). All the variants observed were considered benign in the general population $(33,34)$.

\section{DISCUSSION}

In our cohort, acute onset of headache was the most common symptom of PA and was managed conservatively in patients without visual loss. Radiological evaluation showed that persistent high signal intensity in TIWI lasted longer than usually described in other areas of the brain. Additionally, we showed that AIPmut screening is likely not useful in these patients.

Male predominance was observed to be similar to most series. However, in our cohort, the mean age was 40.5 years, younger than that reported in the literature, in which patients presented most frequently in the $5^{\text {th }}$ or $6^{\text {th }}$ decade of life $(3,9,35-40)$.

Headache was the most frequent symptom, and these results agreed with the literature, in which headache was present in $63 \%-100 \%$ of cases $(29,37,40,41)$. Thunderclap headache was described in approximately $46 \%$ of patients with $\mathrm{PA}$, and we observed similar results (51\%), with no worsening evolution results in this group $(29,37,40,41)$.

Neuroophthalmological symptoms and visual field defects were present in $51 \%(n=18)$ of patients, including ptosis and ophthalmoplegia. These results were similar to the literature, in which a frequency of visual disturbance varying from $23 \%$ to $81 \%(3,42-44)$ and impairment of III, IV and VI cranial nerves of $52 \%$ was described $(3,45)$.

Hypopituitarism is described in 50\%-86\% of all investigated patients $(3,6,45)$. In our study, we observed a frequency of $54 \%$ at admission that progressed to $60 \%$ at the last evaluation. Similarly, other studies showed that improvement in pituitary function after PA, independent of treatment should not be expected $(6,37,42,46)$. One limitation of our study was that we could not precisely estimate the frequency of hypocortisolism in our patients because many patients were admitted to other centers before being transferred to ours and were already using high doses of dexamethasone/hydrocortisone or oral corticosteroids at admission in our center. Additionally, the real 
frequency of GH deficiency could not be determined because we did not perform functional tests, such as the insulin tolerance test, in patients with normal IGF-I levels to ensure that they were not deficient.

The initiation or withdrawal of dopamine agonist; octreotide withdrawal; thrombolytic, anticoagulation and antiplatelet therapy; estrogen therapy; coagulopathies, dengue hemorrhagic fever; cardiac and other major surgeries; dynamic pituitary function tests; radiation therapy; pregnancy and postpartum state have been listed as potential apoplexy precipitating factors $(1,9,12-14,43,47,48)$. In our study, nine patients $(25 \%)$ had arterial hypertension, consistent with the results of other publications, indicating that this condition is a common feature in patients with PA $(3,6,9,13,18)$. However, Möller-Goede and cols. (9) published a review with 574 patients and observed that arterial hypertension and diabetes mellitus did not increase the risk of PA, similar to that in a previous study by Biousse and cols. (13). One patient had syncope during intense exercise that might be related to an abrupt change in tumor vascular pressure, previously described in other conditions associated with an increase in blood pressure (23).

Magnetic resonance imaging is the most important radiological tool to study apoplexy, with sensitivity ranging from $80 \%$ to $90 \%$ (16). Typical MRI descriptions during the acute phase include areas of hyperintense signal on the pituitary region on TIWI $(49,50)$. However, many descriptions of hematoma evolution after apoplexy are derived from what is observed in other parts of the brain, and a lack of specific studies exists to describe hematoma evolution in PA $(30,49)$. Some single-center studies of PA have been reported, but imaging features were, in general, not detailed $(2,36,37)$. Generally, PA imaging studies describe acute events without MRI at follow-up $(15,44,50)$.

The most frequent radiological feature of $\mathrm{PA}$ in the literature is hyperintense signals on TIWI, but other conditions can present the same characteristics, such as aneurysms, lipomas and Rathke cleft cysts (RCCs) (32). T2WI can help in the differentiation of an intracystic hypointense nodule, a typical sign of RCC related to proteinaceous fluid $(32,51)$.

The two most specific image patterns of PA, sphenoid sinus mucosal thickening and fluid debris or fluid-fluid level (hyperintense signal on TIWI in upper fluid), were not found in our series $(15,52)$. The first pattern can appear even before the vascular event, suggesting an engorgement caused by large adenomas or large collections of blood and likely related to severity and generally observed in the acute phase (52). The second pattern is the fluid-fluid level due to free extracellular methemoglobin in the upper fluid layer and with blood residue in the lower layer and is mostly described in the subacute phase (49-52).

A persistent hyperintense signal on TIWI was observed in our series even when MRI was performed in a later period, suggesting slower pituitary hematoma absorption. In vascularized areas of the central nervous system (subdural and epidural areas), oxygen tension remains high and slower from one stage to the next than in the brain itself $(30,49)$. This condition can interfere with the evolution of hematoma and may explain our MRI results in patients outside the acute or subacute phase. Piotin and cols. (50) published an analysis of MRI patterns in PA and showed that, in general, high signal intensity, particularly hyperintensity in TIWI, suggests the presence of blood, but pituitary hemorrhage may present with a persistent hyperintense signal. We found a pituitary ring sign, typically described in the acute phase in a patient who had 30 days of evolution since the occurrence of PA symptoms (Figure 2 A; B) (52).

The risk of re-bleed can occur in a range from $6 \%$ to $11 \%$ of cases described in different studies, and the results are similar regardless of surgical or conservative approach $(15,18,41,45,53)$. We found no apparent re-bleeding, and an empty sella was observed in four of six patients who had undergone a second MRI at IECPN. It took three to eight months after PA for the emergence of an empty sella, suggesting a longer time for hematoma absorption on pituitary topography.

The management of patients with PA can be surgical or conservative, and several retrospective studies

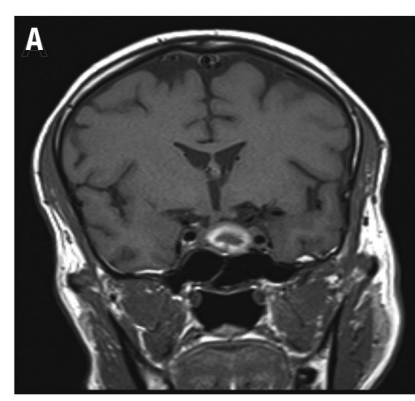

Cor T1WI

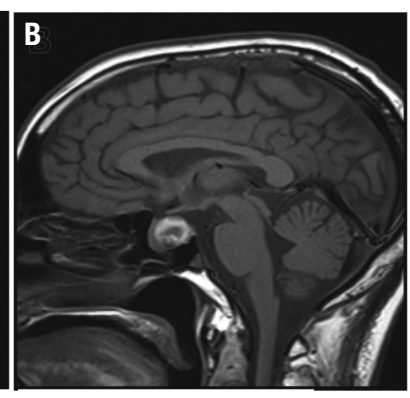

Sag T1WI
Figure 2. Coronal (A) and sagittal T1-weighted imaging (B) sequences of magnetic resonance imaging performed in a patient with classical pituitary apoplexy, 30 days after the acute event and showing a ring area of hyperintense signals in the sellar lesion. 
have shown that the results are similar. In particular, conservative management is performed in patients with mild symptoms and stable ophthalmological deficits $(6,37,40,42)$. Many studies have demonstrated spontaneous resolution of visual and neurological symptoms with expectant management (54-57). However, until now, no randomized trial has compared both strategies $(35,36,39)$. The severity of symptoms at presentation and presence and progression of visual impairment should be considered parameters to guide better treatment for these patients $(6,18,37,40)$. We initially treated 25 patients without visual impairment conservatively despite other neuroophthalmological symptoms (ptosis and/or ophthalmoplegia) with good outcomes.

Some series suggest that apoplexy may be a clinical feature of patients with $A I P$ mutations, as noted by Igreja and cols. (20), who described apoplexy in $8 \%$ of familial series. This mutation is associated with larger tumors with aggressive behavior and a young onset $(21,22,58)$. In our series, AIP screening revealed no mutation $(33,59)$.

Two nonsynonymous SNP variants that promote amino acid substitutions (Q228K and Q307R) were described as missense variants with increased prevalence in FIPA patients (34). In the same study, sporadic forms of Cushing's disease were also associated with a variant of Q307R, and sporadic acromegaly was associated with a variant of Q228K (34). Both allelic variants have already been described in some subpopulations with moderate frequency (59). However, until now, no functional study was performed to confirm the relevance or pathogenicity of these allelic forms, and no other study found an association with FIPA or any other familial disease (59).

Recently, a large study with 2,227 patients analyzed variables that could help in $A I P$ screening and, indeed, apoplexy was more frequent in AIPmut patients. The mechanisms by which AIP mutations may lead to apoplexy may be related to rapid cell growth and proliferation $(3,24)$. However, after multivariate analysis, it was not one of the variables that helped predict patients with an AIPmut (60). Most of the patients included in this study had a family history of pituitary adenomas. In our study, which included only patients with sporadic pituitary adenomas, we also found no AIP mutations, indicating that it is likely not valuable to perform $A I P$ mutation screening in patients with PA.
In conclusion, apoplexy is associated with neuroophthalmological symptoms in a great proportion of patients but can be managed conservatively in selected cases. Images of PA on MRI may not present the classic evolution described for hemorrhagic events in other areas of the central nervous system, with the persistence of areas of hyperintense signals on TIWI after the acute and subacute phases. AIP mutations are not common, and AIP screening should not be performed in the absence of other features suggesting the presence of this mutation.

Disclosure: Mônica R. Gadelha has received unrestricted research grants and lecture fees from Novartis, Ipsen and Pfizer; has participated on advisory boards of Novartis; and is a PI in clinical trials by Novartis and Ipsen. Leandro Kasuki has received lecture fees from Ipsen and Novartis. The other authors have nothing to disclose.

\section{REFERENCES}

1. Nawar RN, AbdelMannan D, Selman WR, Arafah BM. Pituitary tumor apoplexy: a review. J Intensive Care Med. 2008;23(2):75-90.

2. Rajasekaran S, Vanderpump M, Baldeweg S, Drake W, Reddy N, Lanyon M, et al. UK guidelines for the management of pituitary apoplexy. Clin Endocrinol. 2011;74(1):9-20.

3. Randeva HS, Schoebel J, Byrne J, Esiri M, Adams CB, Wass JA. Classical pituitary apoplexy: clinical features, management and outcome. Clin Endocrinol (Oxf). 1999;51(2):181-8.

4. Wakai S, Fukushima T, Teramoto A, Sano K. Pituitary apoplexy: its incidence and clinical significance. J Neurosurg. 1981;55(2):187-93.

5. Matharu MS, Schwedt TJ, Dodick DW. Thunderclap headache: an approach to a neurologic emergency. Curr Neurol Neurosci Rep. 2007;7(2):101-9.

6. Sibal L, Ball SG, Connolly V, James RA, Kane P, Kelly WF, et al. Pituitary apoplexy: a review of clinical presentation, management and outcome in 45 cases. Pituitary. 2004;7(3):157-63.

7. Zayour DH, Selman WR, Arafah BM. Extreme elevation of intrasellar pressure in patients with pituitary tumor apoplexy: relation to pituitary function. J Clin Endocrinol Metab. 2004;89(11):5649-54.

8. Bills DC, Meyer FB, Laws ER Jr, Davis DH, Ebersold MJ, Scheithauer BW, et al. A retrospective analysis of pituitary apoplexy. Neurosurgery. 1993;33(4):602-8; discussion 8-9.

9. Möller-Goede DL, Brandle M, Landau K, Bernays RL, Schmid C. Pituitary apoplexy: re-evaluation of risk factors for bleeding into pituitary adenomas and impact on outcome. Eur $\mathrm{J}$ Endocrinol. 2011;164(1):37-43.

10. Turgut M, OzsunarY, Başak S, Güney E, Kir E, Meteoğlu I. Pituitary apoplexy: an overview of 186 cases published during the last century. Acta Neurochir (Wien). 2010;152(5):749-61.

11. Wildemberg LE, Glezer A, Bronstein MD, Gadelha MR. Apoplexy in nonfunctioning pituitary adenomas. Pituitary. 2018;21(2):138-44.

12. Vassallo M, Rana Z, Allen S. Pituitary apoplexy after stimulation tests. Postgrad Med J. 1994;70(824):444-5.

13. Biousse V, Newman NJ, Oyesiku NM. Precipitating factors in pituitary apoplexy. J Neurol Neurosurg Psychiatry. 2001;71(4):542-5. 
14. Weisberg LA. Pituitary apoplexy. Association of degenerative change in pituitary ademona with radiotherapy and detection by cerebral computed tomography. Am J Med. 1977;63(1):109-15.

15. Boellis A, di Napoli A, Romano A, Bozzao A. Pituitary apoplexy: an update on clinical and imaging features. Insights Imaging. 2014;5(6):753-62.

16. Onesti ST, Wisniewski T, Post KD. Clinical versus subclinical pituitary apoplexy: presentation, surgical management, and outcome in 21 patients. Neurosurgery. 1990;26(6):980-6.

17. Bonicki W, Kasperlik-Zaluska A, Koszewski W, Zgliczyński W, Wislawski J. Pituitary apoplexy: endocrine, surgical and oncological emergency. Incidence, clinical course and treatment with reference to 799 cases of pituitary adenomas. Acta Neurochir (Wien). 1993;120(3-4):118-22.

18. Ayuk J, McGregor EJ, Mitchell RD, Gittoes NJ. Acute management of pituitary apoplexy--surgery or conservative management? Clin Endocrinol (Oxf). 2004;61(6):747-52.

19. Leyer C, Castinetti F, Morange I, Gueydan M, Oliver C, ConteDevolx $B$, et al. A conservative management is preferable in milder forms of pituitary tumor apoplexy. J Endocrinol Invest. 2011;34(7):502-9.

20. Igreja S, Chahal HS, King P, Bolger GB, Srirangalingam U, Guasti $L$, et al. Characterization of aryl hydrocarbon receptor interacting protein (AIP) mutations in familial isolated pituitary adenoma families. Hum Mutat. 2010;31(8):950-60.

21. Hernandez-Ramirez LC, Gabrovska P, Denes J, Stals K, Trivellin G, Tilley D, et al. Landscape of Familial Isolated and Young-Onset Pituitary Adenomas: Prospective Diagnosis in AIP Mutation Carriers. J Clin Endocrinol Metab. 2015;100(9):E1242-54.

22. Beckers A, Aaltonen LA, Daly AF, Karhu A. Familial isolated pituitary adenomas (FIPA) and the pituitary adenoma predisposition due to mutations in the aryl hydrocarbon receptor interacting protein (AIP) gene. Endocr Rev. 2013;34(2):239-77.

23. Chahal HS, Chapple JP, Frohman LA, Grossman AB, Korbonits M. Clinical, genetic and molecular characterization of patients with familial isolated pituitary adenomas (FIPA). Trends Endocrinol Metab. 2010;21(7):419-27.

24. Leontiou CA, Gueorguiev M, van der Spuy J, Quinton R, Lolli $F$, Hassan $S$, et al. The role of the aryl hydrocarbon receptorinteracting protein gene in familial and sporadic pituitary adenomas. J Clin Endocrinol Metab. 2008;93(6):2390-401.

25. Xekouki P, Mastroyiannis SA, Avgeropoulos D, de la Luz Sierra M, Trivellin G, Gourgari EA, et al. Familial pituitary apoplexy as the only presentation of a novel AIP mutation. Endocr Relat Cancer. 2013;20(5):L11-4.

26. Daly $A F$, Tichomirowa MA, Petrossians $P$, Heliövaara $E$, JaffrainRea ML, Barlier A, et al. Clinical Characteristics and Therapeutic Responses in Patients with Germ-Line AIP Mutations and Pituitary Adenomas: An International Collaborative Study. J Clin Endocrinol Metab. 2010;95(11):E373-E83.

27. Cazabat L, Bouligand J, Salenave S, Bernier M, Gaillard S, Parker $F$, et al. Germline AIP mutations in apparently sporadic pituitary adenomas: prevalence in a prospective single-center cohort of 443 patients. J Clin Endocrinol Metab. 2012;97(4):E663-70.

28. Villa $C$, Lagonigro MS, Magri F, Koziak M, Jaffrain-Rea ML, Brauner R, et al. Hyperplasia-adenoma sequence in pituitary tumorigenesis related to aryl hydrocarbon receptor interacting protein gene mutation. Endocr Relat Cancer. 2011;18(3):347-56.

29. Headache Classification Committee of the International Headache Society (IHS). The International Classification of Headache Disorders, 3rd edition (beta version). Cephalalgia. 2013;33(9):629808.

30. Atlas SW, Mark AS, Grossman RI, Gomori JM. Intracranial hemorrhage: gradient-echo MR imaging at $1.5 \mathrm{~T}$. Comparison with spin-echo imaging and clinical applications. Radiology. 1988;168(3):803-7.

31. Di Chiro G, Nelson KB. The volume of the sella turcica. Am J Roentgenol Radium Ther Nucl Med. 1962;87:989-1008.

32. Bonneville F, Cattin F, Marsot-Dupuch K, Dormont D, Bonneville JF, Chiras J.T1 signal hyperintensity in the sellar region: spectrum of findings. Radiographics. 2006;26(1):93-113.

33. Cazabat L, Libe R, Perlemoine K, Rene-Corail F, Burnichon N, Gimenez-Roqueplo AP, et al. Germline inactivating mutations of the aryl hydrocarbon receptor-interacting protein gene in a large cohort of sporadic acromegaly: mutations are found in a subset of young patients with macroadenomas. Eur J Endocrinol. 2007;157(1):1-8.

34. Yarman S, Ogret YD, Oguz FS. Do the Aryl Hydrocarbon Receptor Interacting Protein Variants (Q228K and Q307R) Play a Role in Patients with Familial and Sporadic Hormone-Secreting Pituitary Adenomas? Genet Test Mol Biomarkers. 2015;19(7):394-8.

35. Gondim JA, de Albuquerque LAF, Almeida JP, Bulcao T, Gomes E, Schops M, et al. Endoscopic Endonasal Surgery for Treatment of Pituitary Apoplexy: 16 Years of Experience in a Specialized Pituitary Center. World Neurosurg. 2017;108:137-42.

36. Grzywotz A, Kleist B, Moller LC, Hans VH, Goricke S, Sure U, et al. Pituitary apoplexy - A single center retrospective study from the neurosurgical perspective and review of the literature. Clin Neurol Neurosurg. 2017;163:39-45.

37. Giritharan S, Gnanalingham K, Kearney T. Pituitary apoplexy bespoke patient management allows good clinical outcome. Clin Endocrinol (Oxf). 2016;85(3):415-22.

38. Singh TD, Valizadeh N, Meyer FB, Atkinson JL, Erickson D, Rabinstein AA. Management and outcomes of pituitary apoplexy. J Neurosurg. 2015;122(6):1450-7.

39. Jho DH, Biller BM, Agarwalla PK, Swearingen B. Pituitary apoplexy: large surgical series with grading system. World Neurosurg. 2014;82(5):781-90.

40. Bujawansa S, Thondam SK, Steele C, Cuthbertson DJ, Gilkes CE, Noonan $\mathrm{C}$, et al. Presentation, management and outcomes in acute pituitary apoplexy: a large single-centre experience from the United Kingdom. Clin Endocrinol (Oxf). 2014;80(3):419-24.

41. Pal A, Capatina C, Tenreiro AP, Guardiola PD, Byrne JV, Cudlip S, et al. Pituitary apoplexy in non-functioning pituitary adenomas: long term follow up is important because of significant numbers of tumour recurrences. Clin Endocrinol (Oxf). 2011;75(4):501-4.

42. Elsasser Imboden PN, De Tribolet N, Lobrinus A, Gaillard RC, Portmann L, Pralong F, et al. Apoplexy in pituitary macroadenoma: eight patients presenting in 12 months. Medicine. 2005;84(3):188-96.

43. Semple PL, Webb MK, de Villiers JC, Laws ER, Jr. Pituitary apoplexy. Neurosurgery. 2005;56(1):65-72; discussion -3.

44. Dubuisson AS, Beckers A, Stevenaert A. Classical pituitary tumour apoplexy: clinical features, management and outcomes in a series of 24 patients. Clin Neurol Neurosurg. 2007;109(1):63-70.

45. Briet C, Salenave S, Bonneville JF, Laws ER, Chanson P. Pituitary Apoplexy. Endocr Rev. 2015;36(6):622-45.

46. Silva CM, Lima GA, Machado EO, Van Haute FR, Gadelha MR. Transient central diabetes insipidus followed by pituitary apoplexy treated in a conservative way. Arq Neuro-Psiquiatr. 2008;66(2B):415-7.

47. Wildemberg LE, Neto LV, Niemeyer P, Gasparetto EL, Chimelli L, Gadelha MR. Association of dengue hemorrhagic fever with multiple risk factors for pituitary apoplexy. Endocr Pract. 2012;18(5):e97-e101.

48. Balarini Lima GA, Machado Ede O, Dos Santos Silva CM, Filho PN, Gadelha MR. Pituitary apoplexy during treatment of cystic macroprolactinomas with cabergoline. Pituitary. 2008;11(3):287-92. 
49. Bradley WG Jr. MR appearance of hemorrhage in the brain. Radiology. 1993;189(1):15-26.

50. Piotin M, Tampieri D, Rufenacht DA, Mohr G, Garant M, Del Carpio $\mathrm{R}$, et al. The various MRI patterns of pituitary apoplexy. Eur Radiol. 1999;9(5):918-23.

51. Arita K, Kurisu K, Tominaga A, Sugiyama K, lkawa F, Yoshioka H, et al. Thickening of sphenoid sinus mucosa during the acute stage of pituitary apoplexy. J Neurosurg. 2001;95(5):897-901.

52. Waqar M, McCreary R, Kearney T, Karabatsou K, Gnanalingham KK. Sphenoid sinus mucosal thickening in the acute phase of pituitary apoplexy. Pituitary. 2017;20(4):441-9.

53. Gruber A, Clayton J, Kumar S, Robertson I, Howlett TA, Mansell P. Pituitary apoplexy: retrospective review of 30 patients--is surgical intervention always necessary? Br J Neurosurg. 2006;20(6):379-85.

54. Maccagnan $P$, Macedo CL, Kayath MJ, Nogueira RG, Abucham J. Conservative management of pituitary apoplexy: a prospective study. J Clin Endocrinol Metab. 1995;80(7):2190-7.

55. Verrees M, Arafah BM, Selman WR. Pituitary tumor apoplexy: characteristics, treatment, and outcomes. Neurosurg Focus. 2004;16(4):E6.
56. McFadzean RM, Doyle D, Rampling R, Teasdale E, Teasdale G. Pituitary apoplexy and its effect on vision. Neurosurgery. 1991;29(5):669-75.

57. Santos AB, Franca MM, Hirosawa RM, Marivo M, Zanini MA, Nunes VS. Conservative management of pituitary tumor apoplexy. Arq Bras Endocrinol Metab. 2011;55(5):345-8.

58. Daly AF, Vanbellinghen JF, Khoo SK, Jaffrain-Rea ML, Naves LA, Guitelman MA, et al. Aryl Hydrocarbon Receptor-Interacting Protein Gene Mutations in Familial Isolated Pituitary Adenomas: Analysis in 73 Families. J Clin Endocrinol Metab. 2007;92(5):1891-6.

59. Rowlands C, Urban J, Wikoff D, Budinsky R. An Evaluation of Single Nucleotide Polymorphisms in the Human Aryl Hydrocarbon Receptor-Interacting Protein (AIP) Gene. Drug Metab Pharmacokinet. 2011;26(4):431-9.

60. Caimari F, Hernández-Ramírez LC, Dang MN, Gabrovska $P$, lacovazzo D, Stals K, et al. Risk category system to identify pituitary adenoma patients with AIP mutations. J Med Genet. 2018;55(4):254-60. 